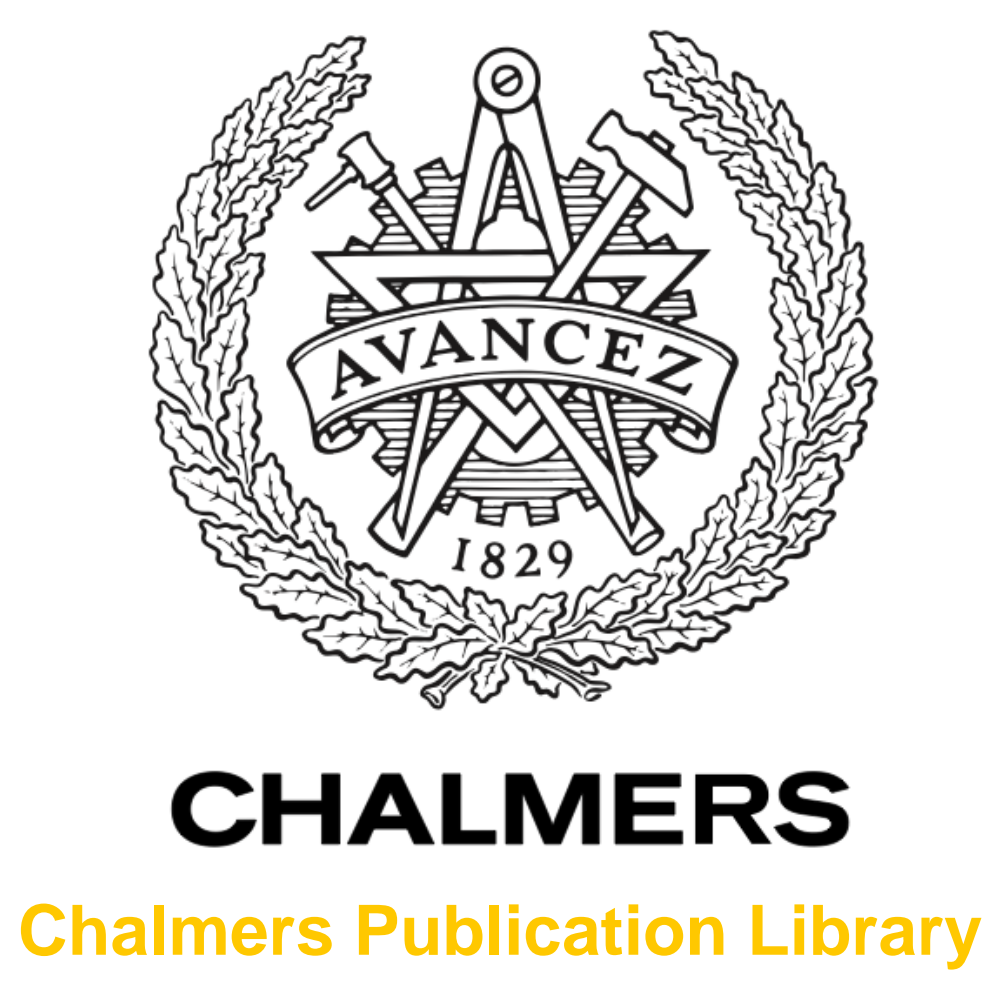

\title{
A Transient Diesel EMS Strategy for Online Implementation
}

This document has been downloaded from Chalmers Publication Library (CPL). It is the author's version of a work that was accepted for publication in:

\section{Preprints of the 19th World Congress The International Federation of Automatic Control Cape Town, South Africa. August 24-29}

Citation for the published paper:

Grahn, M. ; Johansson, K. ; McKelvey, T. (2014) "A Transient Diesel EMS Strategy for Online Implementation". Preprints of the 19th World Congress The International Federation of Automatic Control Cape Town, South Africa. August 24-29 pp. 11842-11847.

Downloaded from: http://publications.lib.chalmers.se/publication/202756

Notice: Changes introduced as a result of publishing processes such as copy-editing and formatting may not be reflected in this document. For a definitive version of this work, please refer to the published source. Please note that access to the published version might require a subscription. 


\title{
A Transient Diesel EMS Strategy for Online Implementation *
}

\author{
Markus Grahn ${ }^{*, * *}$ Krister Johansson* Tomas McKelvey** \\ * Volvo Car Corporation, SE-405 31, Gothenburg, Sweden (e-mail: \\ mgrahn1,kjohan15@volvocars.com). \\ ** Department of Signals and Systems, Chalmers University of \\ Technology, SE-412 96, Gothenburg, Sweden (e-mail: \\ tomas.mckelvey@chalmers.se)
}

\begin{abstract}
A recently developed strategy for diesel engine management systems is modified to reduce the implementation complexity. The strategy calculates set points for engine management system controllable quantities with an aim to minimize fuel consumption for a given engine speed and requested torque profile, while keeping accumulated emissions below given limits. The strategy is based on the methodology for steady-state engine operation, but extended to handle transient effects in the engine caused by dynamics in the air system. The strategy leads to the parametrization of mappings with two, three and four input dimensions respectively. In this paper, a modification of the strategy is proposed such that the memory demanding multidimensional mappings can be approximated in an engine management system using only two-dimensional grid maps. The modified strategy has been evaluated using a complete diesel engine vehicle system model simulating the NEDC driving cycle. The performance of the modified strategy has been compared with the original performance of the strategy. It is demonstrated that the modification of the strategy has very little impact on resulting performance of a vehicle but requires considerably less memory for implementation.
\end{abstract}

Keywords: Diesel engines, Engine management, Optimization, Transient.

\section{INTRODUCTION}

To meet stricter law requirements on emissions and stronger demands on lower fuel consumption, modern passenger car diesel engines become increasingly complex with more and more controllable systems added. Currently, engine control is mostly based on two-dimensional bilinear interpolation maps, commonly denominated as grid maps (Bosch (2003)). The inputs to these maps are the injected fuel amount and the current engine speed, and the outputs are set points for the various controllable engine quantities, e.g. boost pressure, exhaust gas recirculation (EGR) rate, and injection timing. The values in the grid maps are typically calibrated based on steady-state engine operation. A common approach is to approximate a given dynamic vehicle driving cycle as a limited number of steady-state engine operating points, and to calibrate set points in these operating points with respect to engineering targets for the complete cycle. Early work based on this approach for gasoline engine applications can be found in Rishavy et al. (1977); Rao et al. (1979) and early work for diesel engine applications in Schmitz et al. (1994). There are several examples of model-based methods using this approach (Burk et al. (2003); Montgomery and Reitz (2000); Nozaki et al. (2005); Rask and Sellnau (2004); Dimopoulos et al. (1999); Brooks et al. (2005); Knafl et al. (2005); Desantes et al. (2002)). An advantage with the approach is that

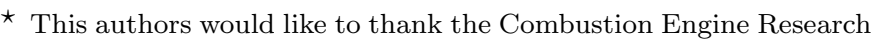
Center (CERC) at Chalmers University of Technology for financial support.
}

optimal set points for steady-state engine operation can be derived from the engine speed and the injected fuel amount only. This means that optimal set points for the complete operating range of the engine can be calculated off-line, and stored in an EMS using for example grid maps. During transient operation, feedback controllers are used to obtain the predefined settings for the air path, however the optimal set points cannot always be directly reached due to dynamics in the engine air path. Additional compensations are then used to keep emissions within a reasonable range. The calibration of these compensations is currently a manual process and is largely performed to meet regulations rather than to optimize the system. Research within the topic of optimizing transient engine operation has mainly been focused on finding optimal actuator trajectories for specified single engine transients. Examples of methods for this are presented in Sequenz et al. (2011), Alberer and del Re (2009) and Benz et al. (2011). These methods are not well suited for online implementation, since optimal trajectories for single transients cannot be directly transferred to a general EMS strategy. Some work has been performed to optimize the EMS in a diesel engine for a complete driving cycle, taking both steady-state and transient engine operation into consideration. Atkinson et. al. has used a model-based approach based on neural networks to achieve a proof-of-concept of the benefit of a model-based transient calibration process Atkinson et al. (2008); Atkinson and Mott (2005). Brahma et. al. has developed a model-based transient calibration process to optimize the parametrization in a standard EMS, taking 
both steady-state and transient engine operation into account Brahma and Chi $(2011 \mathrm{a}, \mathrm{b})$. The approach in their work is to complement the manual work process of performing EMS calibration, rather than to replace it. Based on an existing EMS calibration, simulation models and search algorithms are used to adjust the calibration such that emissions for a dynamic driving cycle are decreased without increasing the fuel consumption.

A novel strategy to calculate set points in a diesel EMS was introduced in Grahn et al. (2013a). The strategy is based on existing methods for steady-state EMS optimization, but extended to handle effects during transient engine operation caused by the dynamics in the engine air system. The method was initially evaluated in Grahn et al. (2013a) using a simple simulation scenario. A fuel consumption decrease potential of up to $0.7 \%$ compared to using an EMS optimization strategy based only on steadystate engine operation was demonstrated. The method was further evaluated in Grahn et al. (2013b) where a complete diesel engine vehicle system simulation model driving according to the New European Driving Cycle (NEDC) was used, and a fuel consumption decrease of $0.56 \%$ was demonstrated. A downside with the approach in Grahn et al. (2013b) is that the set point function maps used linear interpolation maps with a three-dimensional grid map for the oxygen fraction set point, and a fourdimensional grid-map for the injection timing. Such maps are not suitable for on-line implementation in an EMS due to memory space limitations. This paper introduces a modification of the transient EMS optimization strategy. The EMS optimization procedure has been modified such that the required three- and four-dimensional set point maps are described using a regression structure only involving a few two-dimensional bilinear interpolation maps with a significantly smaller EMS memory requirement.

\section{OPTIMIZATION PROBLEM}

The optimization problem for an Engine Management System (EMS) can be formulated as to minimize fuel consumption for a given vehicle driving cycle while fulfilling constraints on accumulated emissions. To fully define this optimization problem mathematically, the complete vehicle system needs to be considered, including driver, engine, EMS, and vehicle. A common method to isolate the engine from this complete optimization problem is to approximate the problem. Typically, the optimization problem is approximated such that the vehicle drive cycle is estimated as a given requested torque profile for the engine. In this study, the considered EMS controllable quantities are boost pressure, oxygen fraction in the intake manifold, and injection timing, hence the approximated optimization problem can be formulated as

$$
\begin{aligned}
& \min _{\boldsymbol{p}_{\mathrm{b}_{\mathrm{set}}}, \mathbf{r}_{\mathrm{O}_{\mathbf{2}} \mathrm{se}}, \varphi} \sum_{i=1}^{N} m_{\mathrm{f}}\left(n_{\mathrm{e} i}, T_{\mathrm{e} i}, p_{\mathrm{b}_{\mathrm{act} i} i}, r_{\mathrm{O}_{2} \text { act } i}, \varphi_{i}\right) \\
& \text { s.t. } \\
& \sum_{i=1}^{N} f_{\mathrm{NO}_{\mathrm{X}}}\left(n_{\mathrm{e} i}, T_{\mathrm{e} i}, p_{\mathrm{b}_{\text {act }} i}, r_{\mathrm{O}_{2} \text { act } i}, \varphi_{i}\right) \leq \mathrm{NO}_{\mathrm{X} l i m} \\
& \sum_{i=1}^{N} f_{\mathrm{soot}}\left(n_{\mathrm{e} i}, T_{\mathrm{e} i}, p_{\mathrm{b}_{\text {act } i}}, r_{\mathrm{O}_{2} \text { act } i}, \varphi_{i}\right) \leq \operatorname{soot}_{\mathrm{lim}}
\end{aligned}
$$

where $N$ is the number of combustion events during the cycle, $\boldsymbol{p}_{\mathbf{b}_{\text {set }}}$ is a vector with set points for the boost pressure $(\mathrm{Pa}), \boldsymbol{r}_{\mathbf{O}_{2} \text { set }}$ is a vector with set points for the oxygen fraction in the intake manifold (-), and $\varphi$ is a vector with injection timings (Crank Angle Degrees (CAD)). The vectors all have $N$ elements, each corresponding to one combustion event throughout the cycle. The function $m_{\mathrm{f}}\left(n_{\mathrm{e} i}, T_{\mathrm{e} i}, p_{\mathrm{bact} i}, r_{\mathrm{O}_{2} \text { act } i}, \varphi_{i}\right)$ is the fuel amount (g) required to deliver torque $T_{\mathrm{e} i}(\mathrm{Nm})$ at engine speed $n_{\mathrm{e} i}$ $(\mathrm{rpm})$, boost pressure $p_{\mathrm{b}_{\text {act } i}}(\mathrm{~Pa})$, oxygen fraction $r_{\mathrm{O}_{2} \text { act } i}$ (-) and injection timing $\varphi_{i}(\mathrm{CAD})$ corresponding to combustion event $i$. The function $f_{\mathrm{NO}}$ is the amount of $\mathrm{NO}_{\mathrm{X}}$ emissions $(\mathrm{g})$, and the function $f_{\text {soot }}$ is the amount of soot emissions (g) at combustion number $i$. $\mathrm{NO}_{\mathrm{X} \lim }$ is the limit on accumulated amount of $\mathrm{NO}_{\mathrm{X}}$ emissions, and soot ${ }_{\text {lim }}$ is the limit on accumulated soot emissions during the cycle. It can be noted that the optimization parameters are set points for boost pressure and oxygen fraction together with the injection timing. Due to dynamics in the engine air system, these set points are not always reached for each combustion.

\section{OPTIMIZATION ALGORITHMS}

\subsection{Steady-State Approach}

A common approach to handle the optimization problem in (1) is to neglect the dynamics in the engine air system. This is achieved by replacing the actual values of boost pressure and oxygen fraction in the optimization problem with the set points for these values. Applying a Lagrangian relaxation approach for this approximated optimization problem will decouple the dependance between the combustions and each combustion can be optimized separately. The optimization problem for each combustion event is

$$
\min _{p_{\mathrm{bset}}, r_{\mathrm{O}_{2} \text { set }}, \varphi}\left(m_{\mathrm{f}}+\lambda_{\mathrm{NO}_{\mathrm{X}}} f_{\mathrm{NO}_{\mathrm{X}}}+\lambda_{\text {soot }} f_{\text {soot }}\right)
$$

where

$$
\begin{aligned}
& m_{\mathrm{f}}=m_{\mathrm{f}}\left(n_{\mathrm{e}}, T_{\mathrm{e}}, p_{\mathrm{b}_{\mathrm{set}}}, r_{\mathrm{O}_{2 \mathrm{set}}}, \varphi\right) \\
& f_{\mathrm{NOx}}=f_{\mathrm{NO}_{\mathrm{x}}}\left(n_{\mathrm{e}}, T_{\mathrm{e}}, p_{\mathrm{b}_{\mathrm{set}}}, r_{\mathrm{O}_{2 \mathrm{set}}}, \varphi\right) \\
& f_{\text {soot }}=f_{\text {soot }}\left(n_{\mathrm{e}}, T_{\mathrm{e}}, p_{\mathrm{b}_{\mathrm{set}}}, r_{\mathrm{O}_{2 \mathrm{set}}}, \varphi\right)
\end{aligned}
$$

The values of the Lagrangian multipliers, $\lambda_{\mathrm{NO}}$ and $\lambda_{\text {soot }}$, can be chosen such that the optimal solution to the approximated problem is found. However, the values are typically chosen such that the constraints for $\mathrm{NO}_{\mathrm{X}}$ and soot emissions are fulfilled in the original optimization problem (1). A gradient search method can be used to find the values. Given the resulting values of the Lagrangian multipliers the calculated set points are only a function of engine speed and requested torque, hence set points for the complete working range of the engine with respect to engine speed and requested torque can be calculated off-line by solving (2), and stored in an EMS using for example two-dimensional grid maps. Therefore, this optimization approach can be implemented as a general EMS strategy that calculates set points for any driving scenario. Typically, the EMS set points are defined by grid maps of the following form

$$
\begin{aligned}
& p_{\mathrm{b}_{\text {set }}}=M_{\mathrm{p}}\left(n_{\mathrm{e}}, m_{\mathrm{f}}\right) \\
& r_{\mathrm{O}_{2 \text { set }}}=M_{\mathrm{r}_{\mathrm{O}_{2}}}\left(n_{\mathrm{e}}, m_{\mathrm{f}}\right) \\
& \varphi=M_{\varphi}\left(n_{\mathrm{e}}, m_{\mathrm{f}}\right)
\end{aligned}
$$


A more detailed description of this optimization procedure can be found in e.g. Rishavy et al. (1977); Rao et al. (1979)

\subsection{Transient Extension}

In Grahn et al. (2013a), a strategy to extend the optimization approach to account also for transient engine operation operation was introduced. The main difference between steady-state and transient engine operation with respect to emissions and fuel consumption is caused by the dynamics in the air system (Glewen et al. (2012)), and the approach is to include states in the engine air system in the optimization algorithm. The approach is also to separate the set points based on their different corresponding time scales, such that set points for faster systems are adjusted when there are dynamics in slower systems. This is performed by using the following strategy. The optimization problem (2) is solved similarly as before. But instead of using the complete solution to this optimization problem, only the set point for boost pressure, $p_{\mathrm{b}_{\mathrm{set}}}$, is used, since the boost pressure set point is associated with the slowest dynamics in the system. Next, a second optimization problem is solved

$$
\min _{r_{O_{2 \mathrm{set}}}, \varphi}\left(m_{\mathrm{f} 2}+\lambda_{\mathrm{NO}_{\mathrm{x}}} f_{\mathrm{NO}_{2}}+\lambda_{\text {soot }} f_{\text {soot } 2}\right)
$$

where

$$
\begin{aligned}
& m_{\mathrm{f} 2}=m_{\mathrm{f}}\left(n_{\mathrm{e}}, T_{\mathrm{e}}, p_{\mathrm{bact}}, r_{\mathrm{O}_{2} \mathrm{set}}, \varphi\right) \\
& f_{\mathrm{NO}_{\mathrm{X} 2}}=f_{\mathrm{NO}_{\mathrm{x}}}\left(n_{\mathrm{e}}, T_{\mathrm{e}}, p_{\mathrm{b} \text { act }}, r_{\mathrm{O}_{2 \mathrm{set}}}, \varphi\right) \\
& f_{\text {soot } 2}=f_{\text {soot }}\left(n_{\mathrm{e}}, T_{\mathrm{e}}, p_{\mathrm{b} \text { act }}, r_{\mathrm{O}_{2 \mathrm{set}}}, \varphi\right)
\end{aligned}
$$

This optimization problem is similar to (2), but with the difference that the optimization problem is only solved for the oxygen fraction set point, $r_{\mathrm{O}_{2} \text { set }}$, and the injection timing, $\varphi$. The boost pressure set point is not included in the optimization, instead the actual boost pressure in the system, $p_{\text {bact }}$, is used as a given input. Finally, a third optimization problem is solved

$$
\min _{\varphi}\left(m_{\mathrm{f} 3}+\lambda_{\mathrm{NO}_{\mathrm{x}}} f_{\mathrm{NO}_{3}}+\lambda_{\text {soot }} f_{\text {soot } 3}\right)
$$

where

$$
\begin{aligned}
& m_{\mathrm{f} 3}=m_{\mathrm{f}}\left(n_{\mathrm{e}}, T_{\mathrm{e}}, p_{\mathrm{b} \text { act }}, r_{\mathrm{O}_{2} \text { act }}, \varphi\right) \\
& f_{\mathrm{NO}_{\mathrm{X}} 3}=f_{\mathrm{NO}_{\mathrm{x}}}\left(n_{\mathrm{e}}, T_{\mathrm{e}}, p_{\mathrm{b} \text { act }}, r_{\mathrm{O}_{2} \text { act }}, \varphi\right) \\
& f_{\mathrm{soot} 3}=f_{\text {soot }}\left(n_{\mathrm{e}}, T_{\mathrm{e}}, p_{\mathrm{b} \text { act }}, r_{\mathrm{O}_{2} \text { act }}, \varphi\right)
\end{aligned}
$$

Again, this optimization is similar to (2) and (4), but with the difference that the optimization problem is solved only for the injection timing, $\varphi$. The values of the Lagrangian multipliers are chosen such that the resulting set points yield a feasible solution to the original optimization problem (1). Given the resulting values of the multipliers, the resulting EMS set points can be defined by grid maps of the following form

$$
\begin{aligned}
& p_{\mathrm{b}_{\text {set }}}=M_{\mathrm{p}}\left(n_{\mathrm{e}}, m_{\mathrm{f}}\right) \\
& r_{\mathrm{O}_{2 \mathrm{set}}}=M_{\mathrm{r}_{\mathrm{O}_{2} \mathrm{cmp}}}\left(n_{\mathrm{e}}, m_{\mathrm{f}}, p_{\mathrm{b} \text { act }}-p_{\mathrm{b}_{\mathrm{set}}}\right) \\
& \varphi=M_{\varphi_{\mathrm{cmp}}}\left(n_{\mathrm{e}}, m_{\mathrm{f}}, p_{\mathrm{b} \text { act }}-p_{\mathrm{b}_{\mathrm{set}}}, r_{\mathrm{O}_{2} \text { act }}-r_{\mathrm{O}_{2 \mathrm{set}}}\right)
\end{aligned}
$$

A more detailed description of this optimization algorithm can be found in Grahn et al. (2013a,b).

\subsection{Modification of transient extension}

To implement the developed EMS optimization approach, the structure in a standard EMS needs to be modified.
The control structure in an EMS today is typically based on two-dimensional grid maps in the form of bilinear interpolation tables (Bosch (2003)), but for the developed EMS optimization strategy, a three-dimensional grid map for the oxygen fraction set point is needed, and a fourdimensional grid-map for the injection timing is needed. It is possible to modify the structure in an EMS according to this, but three- and four-dimensional grid maps require a large amount of storage space in the EMS, and should therefore be avoided if possible. The three-dimensional grid map for the oxygen fraction set point, $M_{\mathrm{r}_{2}}$, in (6) is constructed to compensate for boost pressure deviations, and the four-dimensional grid map for the injection timing, $M_{\varphi}$, is constructed to compensate for boost pressure and oxygen fraction deviations. Based on this, a structure of the following regression form is suggested:

$$
\begin{aligned}
p_{\mathrm{b}_{\text {set }}}= & M_{\mathrm{p}}\left(n_{\mathrm{e}}, m_{\mathrm{f}}\right) \\
r_{\mathrm{O}_{2} \text { set }}= & M_{\mathrm{r}_{\mathrm{O}_{2} \text { base }}}\left(n_{\mathrm{e}}, m_{\mathrm{f}}\right)+ \\
& \left(p_{\mathrm{b}_{\text {act }}}-p_{\mathrm{b}_{\mathrm{set}}}\right) \cdot M_{\mathrm{r}_{\mathrm{O}_{2} \mathrm{cmp}}}\left(n_{\mathrm{e}}, m_{\mathrm{f}}\right) \\
\varphi= & M_{\varphi_{\text {base }}}\left(n_{\mathrm{e}}, m_{\mathrm{f}}\right)+ \\
& \left(p_{\mathrm{b}_{\text {act }}}-p_{\mathrm{b}_{\mathrm{set}}}\right) \cdot M_{\varphi_{\mathrm{cmp}_{1}}}\left(n_{\mathrm{e}}, m_{\mathrm{f}}\right)+ \\
& \left(r_{\mathrm{O}_{2} \text { act }}-r_{\mathrm{O}_{2} \text { set }}\right) \cdot M_{\varphi_{\mathrm{cmp}_{2}}}\left(n_{\mathrm{e}}, m_{\mathrm{f}}\right)
\end{aligned}
$$

This structure can be implemented in an EMS using only two-dimensional grid maps.

\section{SIMULATION MODEL}

To evaluate the EMS optimization strategy a diesel engine vehicle system simulation model has been used. The simulation model is described in detail in Grahn (2012), but a brief description of the model is given here. The simulation model consists of four sub-models; a model for the driver, a model for the EMS, a model for the engine, and a model for the vehicle. A schematic illustration of the simulation model with its sub-models and the interfaces between them is shown in Figure 1. The main focus in the complete simulation model is modeling of the engine with its gas exchange system, combustion and emission formation. The other sub-systems are modeled using simple, physical based models, which capture the main interaction effects with the engine.

\subsection{Engine Model}

The engine model is divided into two sub-models, a model for the engine air system, and a model for the combustion. The air system is implemented as a mean-value model based on the structure described in Wahlström (2009). Models for generated engine torque, $\mathrm{NO}_{\mathrm{X}}$, and soot emissions have been created using a data-driven model structure introduced in Grahn et al. (2012b). The model structure is a regression model with parameters from grid maps in the engine speed and injected fuel amount domain, and is designed to account for effects during transient engine operation caused by dynamics in the engine air system. The models have all been created using steadystate engine measurement data from a Volvo 2.4 liter passenger car diesel engine. The measurements have been performed such that the operating range of the engine regarding boost pressure, oxygen fraction in the intake manifold, and injection timing has been exploited as much 


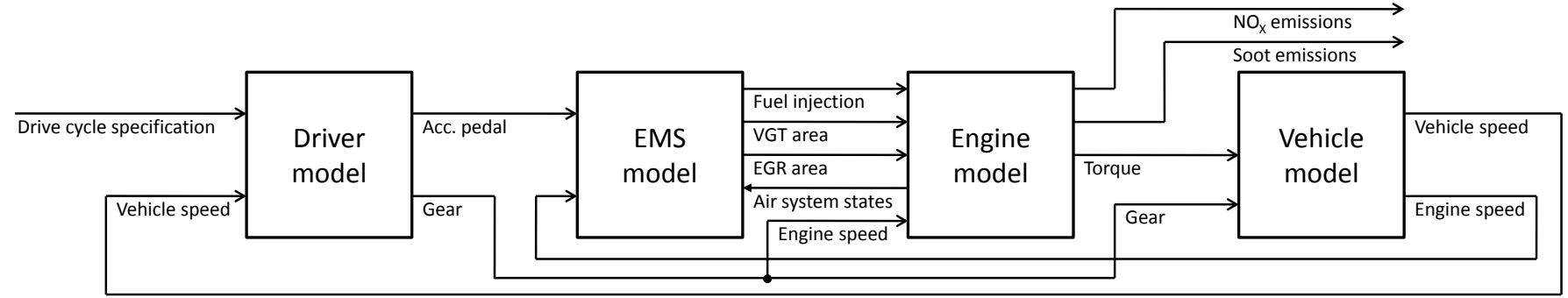

Fig. 1. Schematic illustration of the complete diesel engine vehicle system simulation model with its four sub-models and the main interfaces between them.

as possible using only steady-state engine operation. The produced engine torque, $\mathrm{NO}_{\mathrm{X}}$ emissions, and soot emissions are estimated as

$$
\begin{aligned}
& \hat{T}_{\mathrm{E}}=m_{\mathrm{f}} \cdot\left(f_{\mathrm{T}_{0}}\left(n_{\mathrm{e}}, m_{\mathrm{f}}\right)+\sum_{i=1}^{3} z_{i} \cdot f_{\mathrm{T}_{i}}\left(n_{\mathrm{e}}, m_{\mathrm{f}}\right)\right) \\
& \hat{f}_{\mathrm{NO}_{\mathrm{X}}}=m_{\mathrm{f}} \cdot e^{\left(f_{\mathrm{N}_{0}}\left(n_{\mathrm{e}}, m_{\mathrm{f}}\right)+\sum_{i=1}^{3} z_{i} \cdot f_{\mathrm{N}_{i}}\left(n_{\mathrm{e}}, m_{\mathrm{f}}\right)\right)} \\
& \hat{f}_{\text {soot }}=m_{\mathrm{f}} \cdot e^{\left(f_{\mathrm{s}_{0}}\left(n_{\mathrm{e}}, m_{\mathrm{f}}\right)+\sum_{i=1}^{3} z_{i} \cdot f_{\mathrm{s} i}\left(m_{\mathrm{f}}, n_{\mathrm{e}}\right)\right)}
\end{aligned}
$$

where $\hat{T}_{\mathrm{E}}$ is the estimated produced engine torque $(\mathrm{Nm})$, $\hat{f}_{\mathrm{NO}_{\mathrm{x}}}$ the estimated $\mathrm{NO}_{\mathrm{X}}$ emissions $(\mathrm{g})$, and $\hat{f}_{\text {soot }}$ the estimated soot emissions $(\mathrm{g})$ at injected fuel amount $m_{\mathrm{f}}(\mathrm{g})$, engine speed $n_{\mathrm{e}}(\mathrm{rpm})$, boost pressure $z_{1}(\mathrm{~Pa})$, oxygen fraction $z_{2}(-)$, and injection timing $z_{3}$ (CAD). The functions $f_{\mathrm{T}_{i}}, f_{\mathrm{N}_{i}}$, and $f_{\mathrm{s}_{i}}, i=1 \ldots 4$ are all grid maps with engine speed and injected fuel amount as inputs, created by fitting the models to the engine measurements. Details regarding the prediction performance of these models can be found in Grahn et al. (2012b,a).

\subsection{Engine Management System}

The engine management system calculates set points for boost pressure, oxygen fraction in the intake manifold, and injection timing. The three different algorithms described in Section 3 have been implemented.

The EMS strategy based on steady-state engine operation described in Section 3.1 has been implemented using grid maps with engine speed and injected fuel amount as inputs according to (3). Ten axis points are used in both dimensions of the three grid maps, equally spaced between 750 and 2250 (rpm) for the engine speed and between 0 and $35(\mathrm{mg})$ for the injected fuel amount, resulting in 300 values to store in the EMS. The values in the maps are calculated by solving (2) in each grid point of the maps. The models for generated torque, $\mathrm{NO}_{\mathrm{X}}$, and soot emissions described in Section 4.1 are used in the optimization problems.

The transient extension of the EMS strategy described in Section 3.2 has also been implemented using a structure based on grid maps. Ten axis points are used in all dimensions of all maps. The injected fuel amount is equally spaced between 0 and $35(\mathrm{mg})$, the engine speed is equally spaced between 750 and 2250 (rpm), the boost pressure deviation is equally spaced between $-10^{5}$ and $10^{5}$ $(\mathrm{Pa})$, and the oxygen fraction deviation is equally spaced between -0.1 and $0.1(-)$. The values in the maps for boost pressure set points, oxygen fraction base set points, and injection timing base are calculated by solving (2) in all grid points in the maps. The values in the oxygen fraction compensation grid map are calculated by solving (4) in each grid point, and finally the values in the injection timing compensation map are calculated by solving (5) in each grid point. In total, 1100 values are calculated and stored in the EMS.

The modified transient EMS strategy described in Section 3.3 has also been implemented using a structure based on grid maps according to (7). Also here, ten axis points are used in the both dimensions of all maps, resulting in 600 values to store in the EMS. The method to calculate the values in the six two-dimensional grid maps for given values of the Lagrangian multipliers is as follows:

(1) Calculate the three maps used in the original transient EMS strategy (6)

(2) Perform a simulation of the driving cycle using the original transient EMS strategy. During the simulation, record the values of $n_{e}, m_{\mathrm{f}}, p_{\mathrm{b}_{\mathrm{act}}}, p_{\mathrm{b}_{\mathrm{set}}}, r_{\mathrm{O}_{2} \text { act }}$, $r_{\mathrm{O}_{2} \text { set }}$, and $\varphi$ throughout the simulation

(3) Using the recorded values, calculate the values in the six two-dimensional maps such that the difference between the calculated set points from the modified structure and the recorded values of the set points are minimized in a least squares sense

(4) Perform a simulation of the driving cycle using the modified EMS structure

When calculating the values in the two-dimensional maps that minimize the difference, a B-spline approach is taken. The structures for the set points can be represented as B-spline functions, and data-fitting methods for B-spline functions have been applied. The approach to represent a structure based on two-dimensional grid maps as B-spline function is described in detail in Grahn et al. (2012a).

\section{RESULTS}

Studies were performed to evaluate the proposed modified transient EMS optimization strategy. The NEDC cycle was used. The optimization problem (1) was solved using the three different optimization strategies described in Section 3. The simulation model of the engine has been created using measurements from an engine designed for Euro $\mathrm{V}$ emission standards. Therefore, the constraints on accumulated $\mathrm{NO}_{\mathrm{X}}$ and soot emissions were set to fulfill Euro V requirements. For the NEDC driving cycle, this corresponds to a limit on accumulated amount of $\mathrm{NO}_{\mathrm{X}}$ emissions of $1.98 \mathrm{~g}$, and accumulated amount of soot emissions of $55 \mathrm{mg}$ for the total duration of the cycle. For each strategy, the values of the Lagrangian multipliers were 

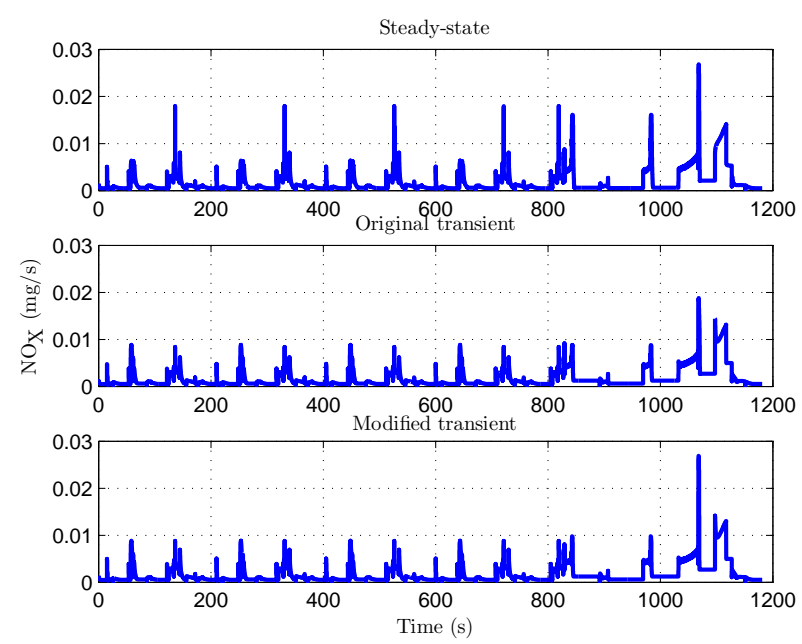

Fig. 2. $\mathrm{NO}_{\mathrm{X}}$ emissions during the NEDC driving cycle for the strategy based on steady-state engine operation (upper), the original transient strategy (middle), and the modified transient strategy (lower).
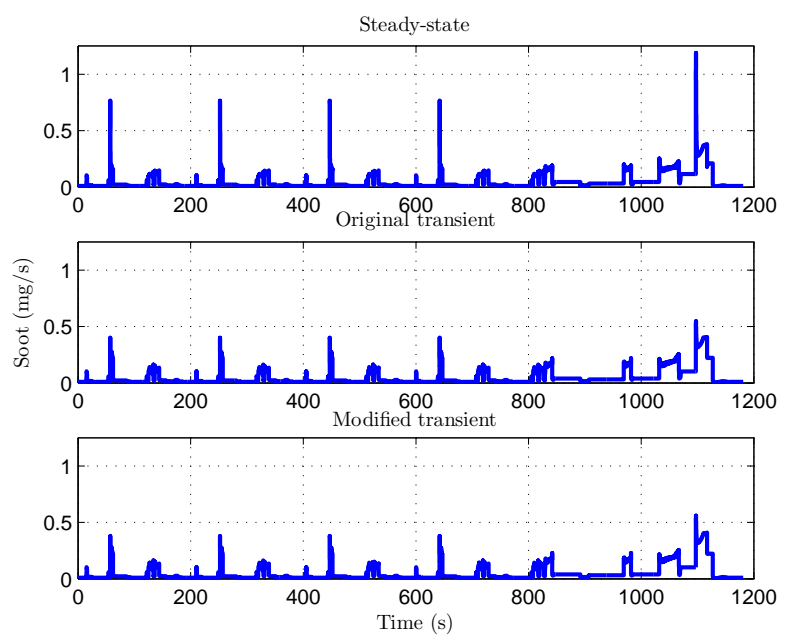

Fig. 3. Soot emissions during the NEDC driving cycle for the strategy based on steady-state engine operation (upper), the original transient strategy (middle), and the modified transient strategy (lower).

chosen such that the emission constraints were fulfilled. The resulting fuel consumption for the three different simulations were compared. For the strategy based on steadystate engine operation, the resulting fuel consumption for the driving cycle was $428.1 \mathrm{~g}$, for the original transient extension strategy the resulting fuel consumption was $425.7 \mathrm{~g}$, and for the modified transient extension strategy proposed in this paper the resulting fuel consumption was $425.8 \mathrm{~g}$. This corresponds to a decrease in fuel consumption of $0.56 \%$ and $0.54 \%$ respectively when using the original transient EMS strategy and the modified transient EMS strategy compared to the strategy based on steady-state engine operation. The resulting $\mathrm{NO}_{\mathrm{X}}$ and soot emissions during the driving cycle for the three different strategies are illustrated in Figure 2 and 3. The emissions during the cycle are different for the three different EMS strategies. The main difference is that the emission peaks during tran-
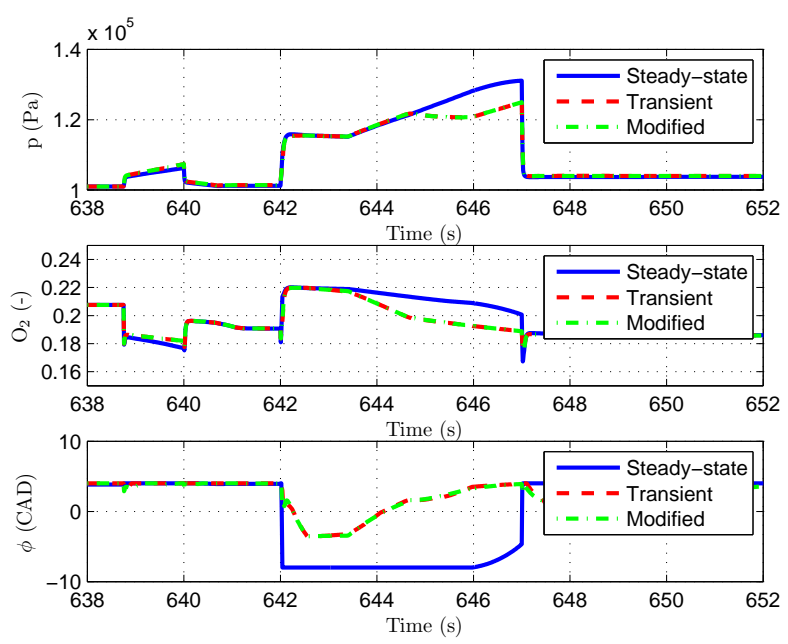

Fig. 4. Set points for boost pressure, oxygen fraction in the intake manifold, and injection timing during a part of the NEDC driving cycle for the three different EMS strategies described in this paper.
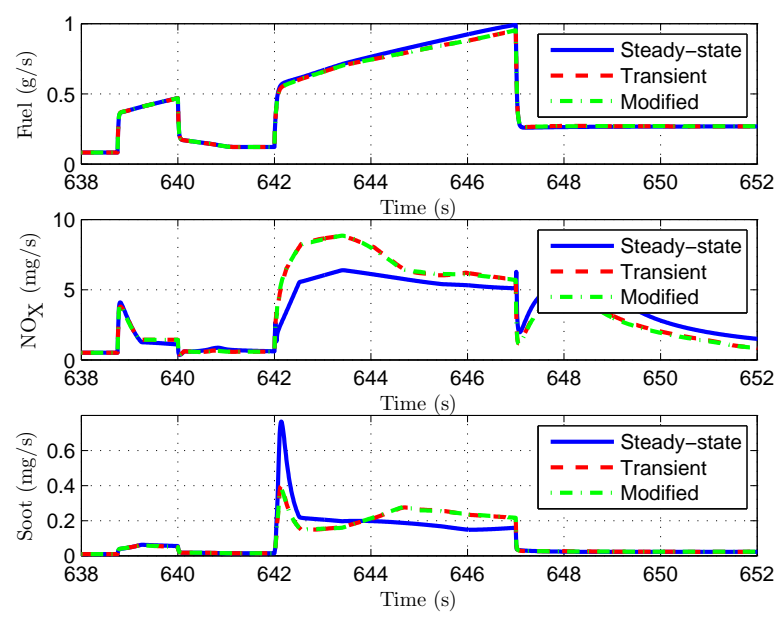

Fig. 5. Fuel consumption, $\mathrm{NO}_{\mathrm{X}}$ emissions, and soot emissions during a part of the NEDC driving cycle for the three different EMS strategies described in this paper.

sient engine operation are typically lower for the transient EMS strategies. The accumulated $\mathrm{NO}_{\mathrm{X}}$ emissions were $1.98 \mathrm{~g}$, and the accumulated soot emissions were $55 \mathrm{mg}$ for all strategies. (The values of the Lagrangian multipliers were chosen to accomplish this.).

To further illustrate the resulting differences between the EMS strategies, the EMS set points for the three strategies during a small part of the simulations are shown in Figure 4 . There are major differences between the strategy based only on steady-state engine operation and the transient strategies, but there is very little difference between the original transient EMS strategy and the modified transient EMS strategy proposed in this paper. The $\mathrm{NO}_{\mathrm{X}}$ and soot emissions, and fuel consumption during the same time period are illustrated in Figure 5. Corresponding differences between the different strategies are seen also in the emissions and fuel consumptions. There are large differences between the steady-state approach and the 
transient approaches, but there are very small differences between the two transient approaches.

\section{CONCLUSION}

Three EMS strategies have been compared using the NEDC driving cycle. One approach based on a steadystate methodology, and two approaches based on explicit transient compensations by using actual boost pressure and oxygen fraction as feed-back signals. The first transient approach uses grid maps in two, three and four dimensions to implement the strategy. The second transient strategy uses only two dimensional grid maps which are considerably less memory demanding. In this study ten axis points were used in all dimensions of all maps, resulting in 11100 values to store in the EMS for the first transient approach, and 600 values for the second transient approach. This corresponds to a memory size reduction of approximately $95 \%$. The simulation results show that the resulting fuel consumption was $428.1 \mathrm{~g}$ for the steadystate method, $425.7 \mathrm{~g}$ for the original transient extension strategy, and $425.8 \mathrm{~g}$ for the modified transient extension strategy proposed in this paper. The less memory demanding approximation using two dimensional grid maps only resulted in a $0.02 \%$ increase in fuel consumption.

\section{REFERENCES}

Alberer, D. and del Re, L. (2009). Optimization of the transient Diesel engine operation. SAE Technical Paper 2009-24-0113.

Atkinson, C., Allain, M., and Zhang, H. (2008). Using Model-Based Rapid Transient Calibration to Reduce Fuel Consumption and Emissions in Diesel Engines. SAE Technical Paper 2008-01-1365.

Atkinson, C. and Mott, G. (2005). Dynamic ModelBased Calibration Optimization: An Introduction and Application to Diesel Engines. SAE Technical Paper 2005-01-0026.

Benz, M., Hehn, M., Onder, C.H., and Guzella, L. (2011). Model-Based Actuator Trajectories Optimization for a Diesel Engine Using a Direct Method. Journal of Engineering for Gas Turbines and Power, 133(023806$1)$.

Bosch (2003). Electronic Diesel Control EDC: Bosch Technical Instruction. Bentley Publishers, Cambridge, USA.

Brahma, I. and Chi, J.N. (2011a). Development of a model-based transient calibration process for diesel engine electronic control module tables - Part 1: data requirements, processing, and analysis. International Journal of Engine Research, 13.

Brahma, I. and Chi, J.N. (2011b). Development of a model-based transient calibration process for diesel engine electronic control module tables - Part 2: modelling and optimization. International Journal of Engine Research, 13.

Brooks, T., Lumsden, G., and Blaxill, H. (2005). Improving Base Engine Calibrations for Diesel Vehicles through the Use of DoE and Optimization Techniques. SAE Technical Paper 2005-01-3833.

Burk, R., Jacquelin, F., and Wakeman, R. (2003). A Contribution to Predictive Engine Calibration Based on Vehicle Drive Cycle Performance. SAE Technical Paper 2003-01-0225.
Desantes, J.M., López, J.J., García, J.M., and Hernández, L. (2002). Application of Neural Networks for Prediction and Optimization of Exhaust Emissions in a H.D. Diesel Engine. SAE Technical Paper 2002-01-1144.

Dimopoulos, P., Schni, A., Eggimann, A., Sparti, C., Vaccarino, E., and Operti, C. (1999). Statistical Methods for Solving the Fuel Consumption/Emission Conflict on DI-Diesel Engines. SAE Technical Paper 1999-01-107\%.

Glewen, W., Heuwetter, D., Foster, D., Andrie, M., and Krieger, R. (2012). Analysis of Deviations from Steady State Performance During Transient Operation of a Light Duty Diesel Engine. SAE Int. J. Engines, 5(3).

Grahn, M. (2012). Diesel Engine Modeling for Engine Management System Development. Licentiate Thesis.

Grahn, M., Johansson, K., and McKelvey, T. (2012a). B-splines for Diesel Engine Emission Modeling. In 2012 Workshop on Engine and Powertrain Control, Simulation and Modeling, 416-423.

Grahn, M., Johansson, K., and McKelvey, T. (2013a). A Diesel Engine Management System Strategy for Transient Engine Operation. 7th IFAC Symposium on Advances in Automotive Control.

Grahn, M., Johansson, K., and McKelvey, T. (2013b). Model-Based Diesel Engine Management System Optimization for Transient Engine Operation. Manuscript submitted for publication.

Grahn, M., Johansson, K., Vartia, C., and McKelvey, T. (2012b). A Structure and Calibration Method for Datadriven Modeling of $\mathrm{NO}_{\mathrm{X}}$ and Soot Emissions from a Diesel Engine. SAE Technical Paper 2012-01-0355.

Knafl, A., Hagena, J.R., Filipi, Z.S., and Assanis, D.N. (2005). Dual-Use Engine Calibration: Leveraging Modern Technologies to Improve Performance - Emissions Tradeoff. SAE Technical Paper 2005-01-1549.

Montgomery, D.T. and Reitz, R.D. (2000). Optimization of Heavy-Duty Diesel Engine Operationg Parameters Using A Response Surface Method. SAE Technical Paper 2000-01-1962.

Nozaki, Y., Fukuma, T., and Tanaka, K. (2005). Development of a Rule-based Calibration Method for Diesel Engines. SAE Technical Paper 2005-01-0044.

Rao, H.S., Cohen, A.I., Tennant, J.A., and Voorhies, K.L.V. (1979). Engine Control Optimization Via Nonlinear Programming. SAE Technical Paper $79017 \%$.

Rask, E. and Sellnau, M. (2004). Simulation-Based Engine Calibration: Tools, Techniques, and Applications. SAE Technical Paper 2004-01-1264.

Rishavy, E., Hamilton, S., Ayers, J., and Keane, M. (1977). Engine Control Optimization for Best Fuel Economy with emission Constraints. SAE Technical Paper 770075.

Schmitz, G., Oligschläger, U., and Eifles, G. (1994). Automated System for Optimized Calibration of Engine Management Systems. SAE Technical Paper 940151.

Sequenz, H., Mrosek, M., Zydek, S., and Isermann, R. (2011). Model Based Optimisation of a Step in Acceleration for a CR-Diesel Engine. In Proceedings of the $6^{\text {th }}$ IFAC Symposium Advances in Automotive Control, 13016-13021.

Wahlström, J. (2009). Control of EGR and VGT for Emission Control and Pumping Work Minimization in Diesel Engines. Ph.D. thesis, Linköping University. 